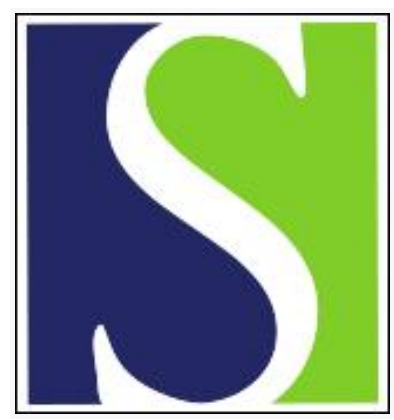

Scand J Work Environ Health 2016;42(6):557-560

https://doi.org/10.5271/sjweh.3585

Published online: 22 Aug 2016, Issue date: 01 Jun 2016

Critical reflections on the currently leading definition of sustainable employability

by Fleuren BPI, de Grip A, Jansen NWH, Kant I, Zijlstra FRH

The commentary reflects on the recently published definition of sustainable employability by van der Klink et al (Scand J Work Environ Health. 2016;42(1):71-9). In doing so, both merits and needs for further improvement are identified, which are translated to guidelines for future definitions of sustainable employability. Consequently, the commentary adds to the discussion on what sustainable employability is and how it should be measured.

Affiliation: Department of Work- and Social Psychology, Faculty of Psychology and Neuroscience, Maastricht University, Universiteitssingel 40, P.O. Box 616, 6200 MD Maastricht, The Netherlands. bram.fleuren@maastrichtuniversity.nl

Refers to the following texts of the Journal: 2016;42(1):34-42 2016;42(1):71-79

The following articles refer to this text: 2018;44(2):134-146; 2018;44(5):475-484

Key terms: Amartya Sen; capability approach; commentary; definition; employability; model; quality of working life; sustainable employability; work

This article in PubMed: www.ncbi.nlm.nih.gov/pubmed/27548816 


\title{
Critical reflections on the currently leading definition of sustainable employability
}

\author{
By Bram PI Fleuren, MSc, ${ }^{1}$ Andries de Grip, PhD, $2,3,4$ Nicole WH Jansen, PhD, ${ }^{5}$ IJmert Kant, PhD, ${ }^{5}$ \\ Fred $R H$ Zijlstra PhD ${ }^{1}$
}

\begin{abstract}
Fleuren BPI, de Grip A, Jansen NWH, Kant I, Zijlstra FRH. Critical reflections on the currently leading definition of sustainable employability. Scand J Work Environ Health. 2016;42(6):557-560. doi:10.5271/sjweh.3585
\end{abstract}

Sustainable employability (SE) is an important topic as it deals with employees' abilities to function adequately at work and in the labor market throughout their working lives. However, until now there has been only one attempt to define SE in the international literature (1). This first definition is a valuable contribution to the field as it rightfully describes $\mathrm{SE}$ as a multidimensional concept, recognizes the importance of both employee and work characteristics, and acknowledges the inherently longitudinal nature of SE. Despite these merits, we argue that this definition of SE has some serious omissions that are important in capturing SE comprehensively. Specifically, we argue that the definition could be improved in various ways, namely, it should: (i) clarify which aspects of employment constitute someone's SE; (ii) not counterintuitively treat $\mathrm{SE}$ as a characteristic of both the job and the employee simultaneously; (iii) not be based on the insufficiently tested assumption that achieving value in work inherently leads to SE; (iv) be formulated in a way that SE can also apply to unemployed individuals; and (v) adequately specify how the inherently longitudinal dimension of SE should be addressed. We would like to contribute to the discussion by providing guidelines for a new adjusted definition of SE that could facilitate further research on this important concept and its determinants.

\section{Introduction}

SE is a topic of vital importance to individual employees, organizations and society alike. It generally refers to employees' capacities to function in work throughout their working life. As participation in work is important for individuals, organizations, and society as a whole, individuals' ability to function in work is essential. For individuals, work provides meaning, financial security as well as social contacts. Organizations need productive employees to survive. Also from a societal perspective, it is important that as many people as possible participate in the labor market to maintain economic welfare (1). Moreover, as a consequence of population aging (2-6), longevity, rapid changes in technology (7, 8 ) and changes in the nature of work (1), both the need to promote sustainable employability of individuals in society and the complexity to succeed in doing so increase even further.

Only recently, van der Klink et al provided the first definition of the concept in the international scientific literature (1, p74): "Sustainable employability means that throughout their working lives, workers can achieve tangible opportunities in the form of a set of capabilities. They also enjoy the necessary conditions that allow

1 Department of Work- and Social Psychology, Faculty of Psychology and Neuroscience, Maastricht University, Maastricht, The Netherlands.

2 Research Center for Education and the Labour Market, School of Business and Economics, Maastricht University, Maastricht, The Netherlands;

3 IZA (Institute for the Study of Labor), Bonn, Germany.

4 Netspar (Network for Studies on Pensions, Ageing and Retirement), Tilburg University, Tilburg, The Netherlands.

5 Department of Epidemiology, CAPHRI School for Public Health and Primary Care, Faculty of Health, Medicine and Life Sciences, Maastricht University, Maastricht, The Netherlands.

Correspondence to: Bram Fleuren, Department of Work- and Social Psychology, Faculty of Psychology and Neuroscience, Maastricht University, Universiteitssingel 40, P.O. Box 616, 6200 MD Maastricht, The Netherlands. [E-mail: bram.fleuren@maastrichtuniversity.nl] 
them to make a valuable contribution through their work, now and in the future, while safeguarding their health and welfare. This requires, on the one hand, a work context that facilitates this for them and, on the other, the attitude and motivation to exploit these opportunities."

This definition is accompanied by an equally recent operationalization of SE as a set of capabilities (9). Moreover, the definition itself also appeared in an earlier Dutch publication (10), which other international publications about SE most commonly refer to [ie, in comparison with other definitions in the non-international (eg, Dutch) literature] (11-13). As mentioned, the present paper provides a critical reflection on van der Klink et al's aforementioned definition of SE (1).

\section{Merits}

Van der Klink et al's definition of SE (1) has three important merits. First, SE is seen as a multidimensional construct. It is presented as consisting of a broad set of opportunities for employees to create value for themselves and for their employer that cover various aspects of working. Moreover, the individual's health and well-being as well as attitudinal and motivational aspects are included in the definition as well. This acknowledgement of the multidimensionality of SE is favorable, as it illustrates the complexity of the construct and of what constitutes functioning in work. This is in accordance with the International Classification of Functioning, Disability and Health (ICF) (14), in which functioning is seen from three different perspectives (body, activities, and participation). The ICF underlines the multifaceted and complex nature of functioning in which disease, environmental factors, and personal factors play a role. Similarly, the multifaceted nature of functioning is also illustrated by the fact that different disciplines focus on different aspects to understand functioning at work $(15,16)$.

Second, SE is (partially) defined as the degree to which (i) employees are able to work throughout their entire working lives, and (ii) their work context enables them to do so. This suggests that SE is a set of interacting characteristics of the employee and the work context that codetermine the opportunities and conditions affecting employees' capacity to participate in the labor market throughout their working lives. As such, the definition describes an equal responsibility for employee and employer to maintain the employee's ability to work. This could be considered as a great merit, as research shows how strongly an employee's ability to function is influenced by both the individual, work and work-contextual factors (17).
Third, van der Klink et al's definition recognizes that SE is an inherently longitudinal construct as clearly embedded in the words "throughout their working lives". This is essential as "sustainable" necessarily implies a time dimension.

\section{Need for further development}

Despite the aforementioned merits, there are important needs for improvement of van der Klink et al's definition of SE.

First, it is not immediately clear from the definition what particular element(s) of the work situation constitute(s) SE. The paper provides some clarity by equating SE with the capability set it propagates, as evidenced by these statements: “. . in an accompanying paper also published in this issue, we report on the development and validation of a questionnaire that allows for the assessment of sustainable employability based on the concept of capability" $(1, \mathrm{p} 72)$ and "This [capability] set, in our view, represents the best possible operationalization of sustainable employability" (1, p74). However, in the paper, SE is also referred to as being determined by a worker's capability: "this model holds that an individual's sustainable employability is determined by how he or she succeeds in converting resources into capabilities, and subsequently into work functioning, in such a way that values such as security, recognition and meaning are met" $(1, p 72)$. As it is not feasible that $\mathrm{SE}$ is predicted by itself in the form of a capability set, perhaps the capability set does not actually refer to SE itself but rather to a favorable employment situation that may cause SE. More clarity on this issue is needed.

Second, the definition seems to treat SE as a characteristic of both the job and the individual at the same time. This is counterintuitive and problematic as the job and work context may predict an individual's ability to be sustainably employed, but they can never be aspects that are part of SE. Instead, employability is a characteristic of the individual alone. Of course the individual's ability to be employed does depend on work and work-contextual factors, but these should be predictors and not be embedded in the construct itself. For an adequate definition of SE, it is essential to disentangle these relationships between causes (employment) and effects (employability). Moreover, future approaches should treat SE as an individual characteristic that is an outcome of the complex interaction between other individual, work, and work-contextual characteristics.

Third, the definition and operationalization of SE assume that achieving value in work inherently predicts SE and that, therefore, SE can be conceptualized as 
achieving value in work. This is problematic, as before such claims can be made, such relationships need to be tested with SE as criterion. This is, however, impossible within the approach van der Klink et al provides. (1), as $\mathrm{SE}$ is equated with its predictor(s). Therefore, similar to the first conceptual issue, it seems unlikely that the capability set adequately reflects SE.

Fourth, the definition by van der Klink et al (1) suggests that SE only applies to individuals who are employed. In the Abma et al publication (9), which accompanies van der Klink's definition paper as a validation paper, this is shown by the way in which capabilities are measured. Moreover, the definition also suggests this because individuals can only be considered to be sustainably employable if their work context enables them to achieve tangible opportunities. However, individuals who are not currently working can still be highly employable and even sustainably so, but just be between jobs. It is therefore not required for individuals to be enabled by their employer to be sustainably employable. Consequently, in line with our aforementioned points on improving the definition, being enabled by an employer to achieve value may be an important predictor of SE, but it is not necessarily part of SE itself. Moreover, future approaches to SE should define the concept in such a way that it is applicable to every individual regardless of employment status.

Finally, the definition and operationalization of SE in the form of a capability set do not include any specification on how the longitudinal aspect of SE should be captured. The definition rightfully acknowledges the longitudinal dimension of SE, but its operationalization focuses solely on achieving value. Although achieving value at work may be an important predictor of SE, a complete operationalization and definition should include its longitudinal nature as well.

\section{Outlook}

In conclusion, while van der Klink et al's definition of SE (1) does have strong merits, it requires further improvement. The approach's main drawback is that capabilities seem more apt at describing a potentially important set of predictor(s) of SE than at capturing the construct itself. Either way, future developments in conceptualizing SE should build on the aforementioned merits, but also define SE in a way that (i) clearly labels which aspects of the employment situation constitute SE; (ii) explicitly separates causes and effects; (iii) treats $\mathrm{SE}$ as an individual characteristic that may be affected by other employment characteristics at the individual, work, and work-contextual levels; (iv) makes the concept applicable to any individual regardless of their employment status; and (v) clearly addresses the longitudinal nature of SE as embedded in the word "sustainable". These guidelines should not only enable the development of an appropriate definition of SE but also a conceptually sound way of measuring the construct.

\section{References}

1. van der Klink JJL, Bültmann U, Burdorf A, Schaufeli WB, Zijlstra FRH, Abma FI, et al. Sustainable employability definition, conceptualization, and implications: A perspective based on the capability approach. Scand J Work Environ Health. 2016;42(1):71-9. http://dx.doi.org/10.5271/sjweh.3531

2. UN. World population aging 2009. New York: United Nations; 2009.

3. Bos D, von Weizsacker RK. Economic consequences of an aging population. Eur Econ Rev. 1989;33:345-54.

4. Bloom DE, Canning D, Sevilla J. The demographic dividend: a new perspective on the economic consequences of population change. Santa Monica, CA: RAND; 2003.

5. Alemayehu B, Warner KE. The lifetime distribution of health care costs. Health Serv Res. 2004;39(3):627-42. http://dx.doi. org/10.1111/j.1475-6773.2004.00248.x

6. Shah MN, Bazarian JJ, Lerner EB, Fairbanks RJ, Barker WH, Auinger P, et al. The epidemiology of emergency medical services use by older adults: an analysis of the National Hospital Ambulatory Medical Care Survey. Acad Emerg Med. 2007;14:441-7.

7. Autor DH, Levy F, Murnane RJ. The skill content of recent technological change: An empirical exploration. Q J Econ. 2003;118(4):1279-333. http://dx.doi. org/10.1162/003355303322552801

8. Machin S, van Reenen J. Technology and changes in skill structure: Evidence from seven OECD countries. Q J Econ. 1998;113(4):1215-44. http://dx.doi. org/10.1162/003355398555883

9. Abma FI, Brouwer S, de Vries HJ, Arends I, Robroek SJW, Cuijpers MPJ, et al. The capability set for work: development and validation of a new questionnaire. Scand J Work Environ Health. 2016;42(1):34-42. http://dx.doi.org/10.5271/ sjweh.3532

10. van der Klink JJL, Brouwer S, Bultmann U, Burdof L, Schaufeli WB, van der Wilt GJ, et al. Duurzaam inzetbaar: Een werkdefinitie [Sustainable employability: A working definition]. Den Haag: ZonMw 2010.

11. van Holland BJ, De Boer MR, Brouwer S, Soer R, Reneman MF. Sustained employability of workers in a production environment: design of a stepped wedge trial to evaluate effectiveness and cost-benefit of the POSE program. Bmc Public Health. 2012;12:1003-11. http://dx.doi. org/10.1186/1471-2458-12-1003

12. Brouwers LAM, Engels JA, Heerkens YF, van der Beek AJ. Development of a vitality scan related to workers' sustainable 
employability: a study assessing its internal consistency and construct validity. 2015;15:511-9. http://dx.doi.org/10.1186/ s12889-015-1894-Z

13. Peters V, Engels JA, de Rijk AE, Nijhuis FJN. Sustainable employability in shiftwork: related to types of work schedule rather than age. Int Arch Occup Environ Health. 2015. http:// dx.doi.org/10.1007/s00420-014-1015-9

14. World Health Organization (WHO). International classification of functioning, disability and health (ICF). Geneva: WHO; 2001.

15. Brewer GD. The challenges of interdisciplinarity. Policy Sci. 1999;32(4):327-37. http://dx.doi. org/10.1023/A:1004706019826
16. Fuchs VR. The future of health economics. J Health Econ. 2000;19(2):141-57. http://dx.doi.org/10.1016/S01676296(99)00033-8

17. Kristof-Brown AL, Zimmerman RD, Johnson EC. Consequences of individuals' fit at work: A meta-analysis of person-job, person-organization, person-group, and personsupervisor fit. Pers Psychol. 2005;58(2):281-342. http:// dx.doi.org/10.1111/j.1744-6570.2005.00672.x

Received for publication: 29 June 2016 